\title{
Art and photonics
}

\section{Dan Curticapean, Oliver Vauderwange, Benjamin Heitz}

Dan Curticapean, Oliver Vauderwange, Benjamin Heitz, "Art and photonics," Proc. SPIE 11143, Fifteenth Conference on Education and Training in Optics and Photonics: ETOP 2019, 111431R (2 July 2019); doi: 10.1117/12.2523415 


\title{
Art and Photonics
}

\author{
Dan Curticapean ${ }^{\mathrm{a}}$, Oliver Vauderwange ${ }^{\mathrm{a}}$, Benjamin Heitz ${ }^{\mathrm{a}}$ \\ ${ }^{a}$ Offenburg University, Badstr. 24, 77652 Offenburg, Germany
}

Keywords: Art and Photonics, Education in Optics and Photonics, International Year of Light, IYL, International Day of Light, IDL

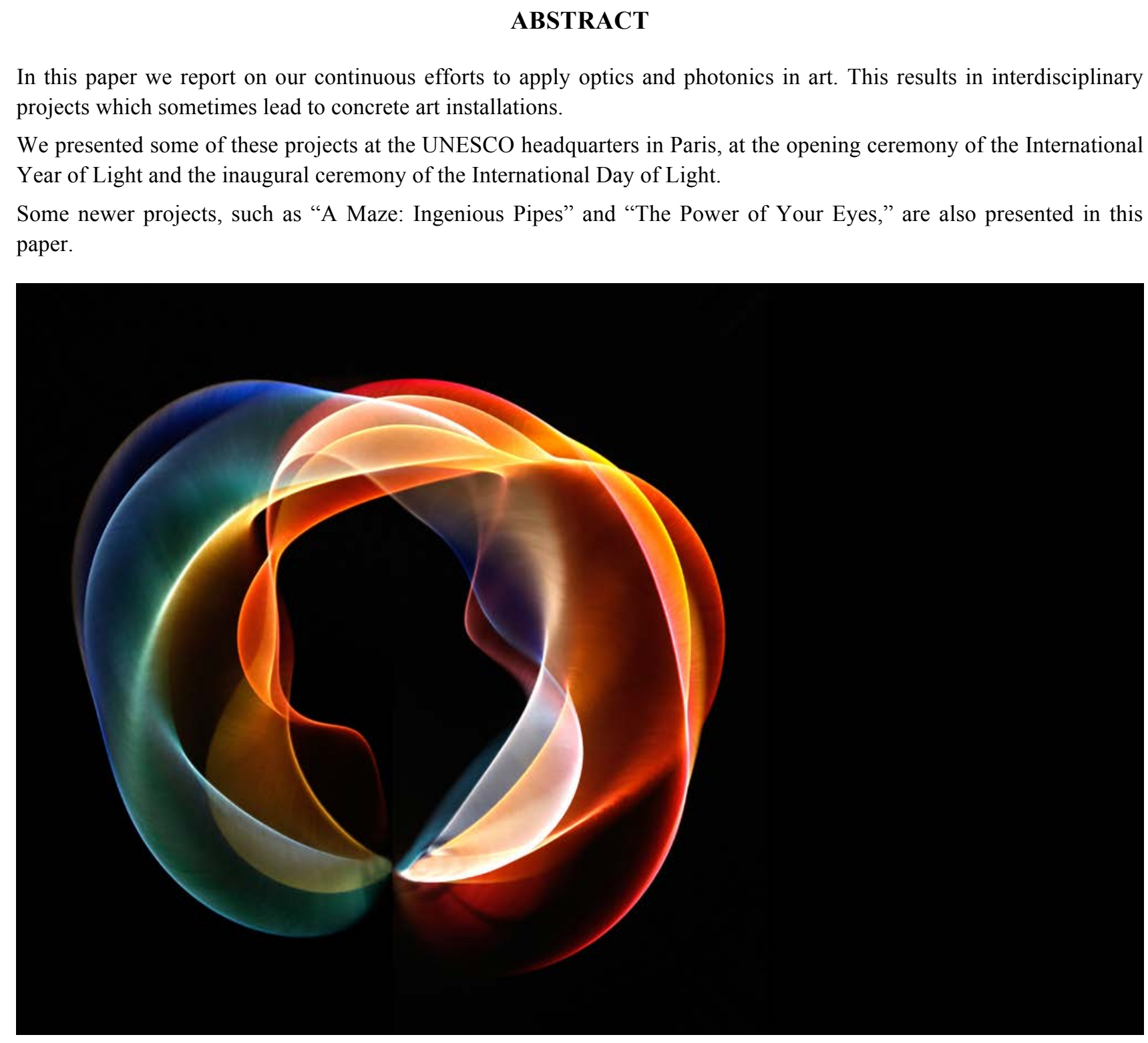

Fig. 1: Optical Möbius Strip II; C Photo Dan Curticapean

* dan.curticapean@hs-offenburg.de, phone 0049781205 372, offenburg-university.de/curticapean

Fifteenth Conference on Education and Training in Optics and Photonics: ETOP 2019, edited by Anne-Sophie Poulin-Girard, Joseph A. Shaw, Proc. of SPIE Vol. 11143, 111431R · (c) 2019 SPIE, ICO, IEEE, OSA · CCC code: 0277-786X/19/\$18 · doi: 10.1117/12.2523415 


\section{INTRODUCTION}

Humans have forever been involved with art. Some of the oldest surviving works of art, created during the Stone Age, are the Venus of Willendorf/Austria and the cave paintings from southern France, such as the Lascaux or the ChauvetPont-d'Arc Caves.

Art is unimaginable without photonics. For the visual arts it is a matter of course. Pictures must be painted but also be viewed. Famous painters such as Rembrandt developed techniques to make the light reflected by the painting appear particularly warm to the viewer, or to create special perspectives from one side versus from the other side.

Nevertheless, both art and science are greatly shaped by their times. Even if the world of art evolved independently from science and technology, it did avail itself of them. Early Renaissance artists such as Da Vinci, Michelangelo and Raphael were universal geniuses of their time and combined the arts with science. They refined their painting techniques not only by developing higher-quality paint colors, but also by studying light, an elementary component of art. Albrecht Dürer, for instance, carried out extensive research to reproduce light as realistically as possible. His findings had a decisive impact on the further development of painting. Three centuries later, the impressionists, as for example Claude Monet, were intent on capturing the mood of light in their pictures. Throughout their lives, they worked on refining a variety of special techniques in order to achieve this aim.

With the invention of photography in the mid-nineteenth century [1], light design entered a new era. It was now possible to capture light directly, and thus form and frame it as well. Another milestone was the transition from analog to digital photography. If analog photography can still be interpreted as light painting, digital photography in comparison is light measurement - and as such, an element of photonics.

Art has developed rapidly since the beginnings of digital technology. The works of established artists, such as David Hockney, have significantly contributed to this development [2], while thanks to the advance of photonics, the necessary technology has become accessible to the broader public.

The using of mobile letters since 1450 revolutionized the method of book printing and triggered a media revolution in Europe. Gutenberg's book printing quickly spread throughout Europe and later throughout the world, and the Renaissance is seen as a key element of the knowledge revolution of the time. In particular, his major work, the Gutenberg Bible, written between 1452 and 1454, led to fundamental social, cultural and political changes [3] - [4].

Nevertheless, even today we are experiencing fascinating times, as similar changes are occurring with the Internet and rapidly evolving Artificial Intelligence.

Today, in contrast to earlier times, we have the possibility to do not only analog art but also digital art. It is impossible to imagine digital art without photonics, both in its creation and its distribution. Art installations, events or projections have to be illuminated and put into scene accordingly; music and acoustic events have to be composed and reproduced - also impossible without light.

Imagine if you had told people more than 550 years ago that books today were written electronically and distributed through air and fiber optics. Photonics again plays a role here. Even more exciting is the question of how books will be written and distributed in the next five hundred years!

Computing capacity has developed so strongly in the last decades that today we can fall back on a strong artificial intelligence. This even enables us not only to create works of art, but also to restructure the history of art from the machine's point of view. Ahmed Elgammal, Professor of Computer Science at the University of Rutgers, and colleagues from the College of Charleston in South Carolina, have researched how computers can facilitate and even complement the work of art historians. They taught the machines to distinguish images by means of visual features. They based their work on the theory of the Swiss art historian Heinrich Wölfling that paintings should only be classified according to their formal characteristics and not, like their predecessors, according to content and expression. They came up with new interesting results, as for example that Cézanne's works form a bridge between Impressionism and Cubism [5]. 
There are more and more exhibitions today showing the art of robots or artificial intelligence, for example, the Paris exhibition "Artists and Robots" at the Grand Palais (Spring 2018) or the exhibitions of the AICAN (Artificial Intelligence Creative Adversarial Network - Algorithms) presented in Frankfurt, Los Angeles, New York and San Francisco (Fall 2017) [5].

This also opens up new questions of copyright law: who has the rights to the works of art of the AI?

Yet another reference to the connection between art and photonics is the international prize for digital art, the Lumen Prize.

\section{PREVIOUS SUCCESSFUL ART PROJECTS CREATED AT OUR UNIVERSITY DEDICATED TO OPTICS AND PHOTONICS}

Selected examples of this interdisciplinary project are shown in figure 2 below. Students were also encouraged to bring in their own ideas in the creation of the art posters.

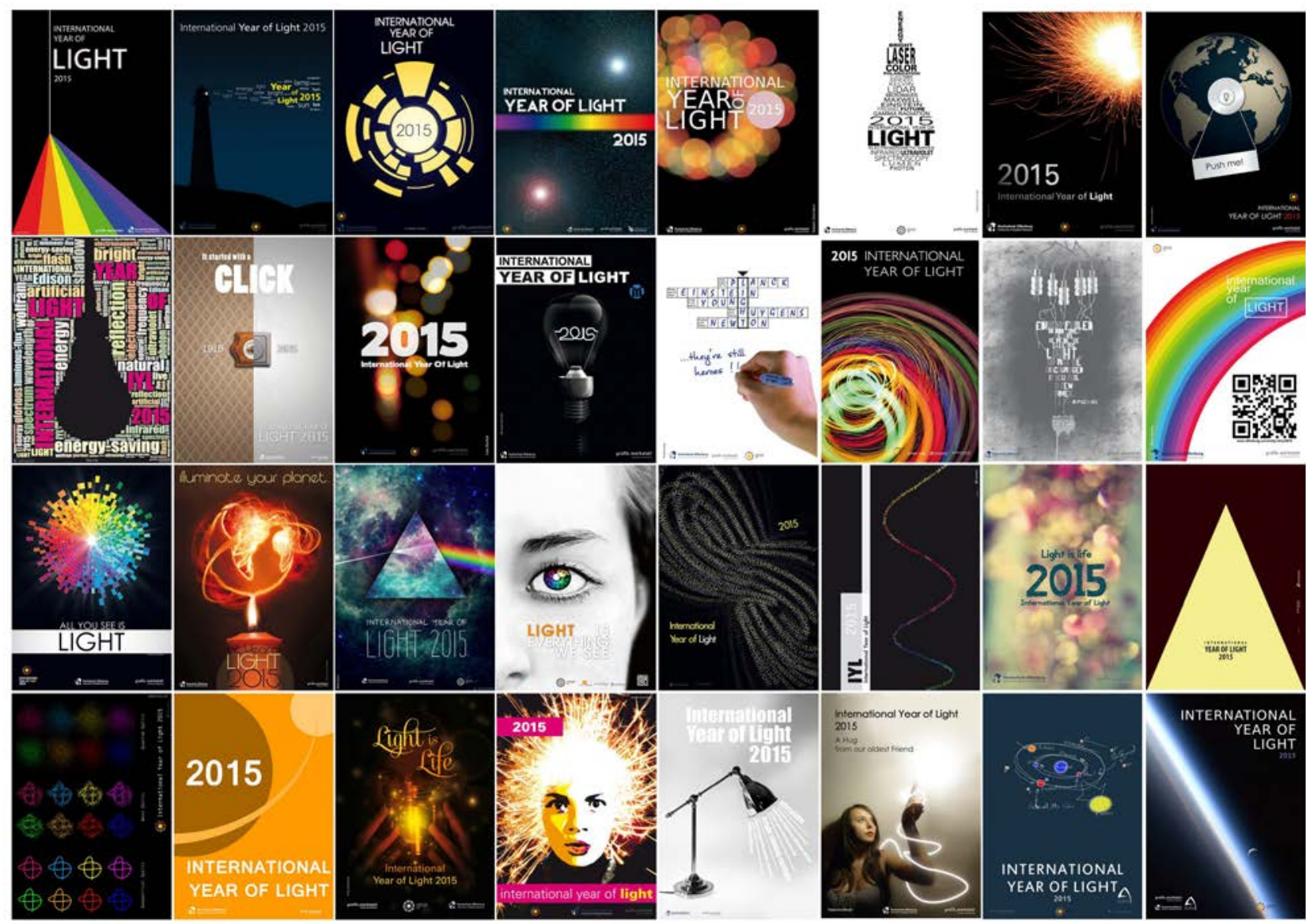

Fig. 2: Art-Poster collection dedicated to the IYL 2015; C www.Offenburg-University.de/curticapean 
Due to the first successes, in 2010 to the topic "50 Years of Laser" and 1015 to the topic IYL also other events were considered by our students. Especially the FIFA World Cup was discussed, which resulted in the independent poster series, "No football - just photonics." The core idea of the series was to transfer optical components and devices:

- an optical comb generator,

- Raman scattering,

- a photo coupler,

- an optical ring resonator,

- an optical fiber,

- an optical amplifier,

- a Mach-Zehnder coupler,

- erbium-doped fiber amplifiers,

all working their magic on a soccer field (see figure 3). [6]
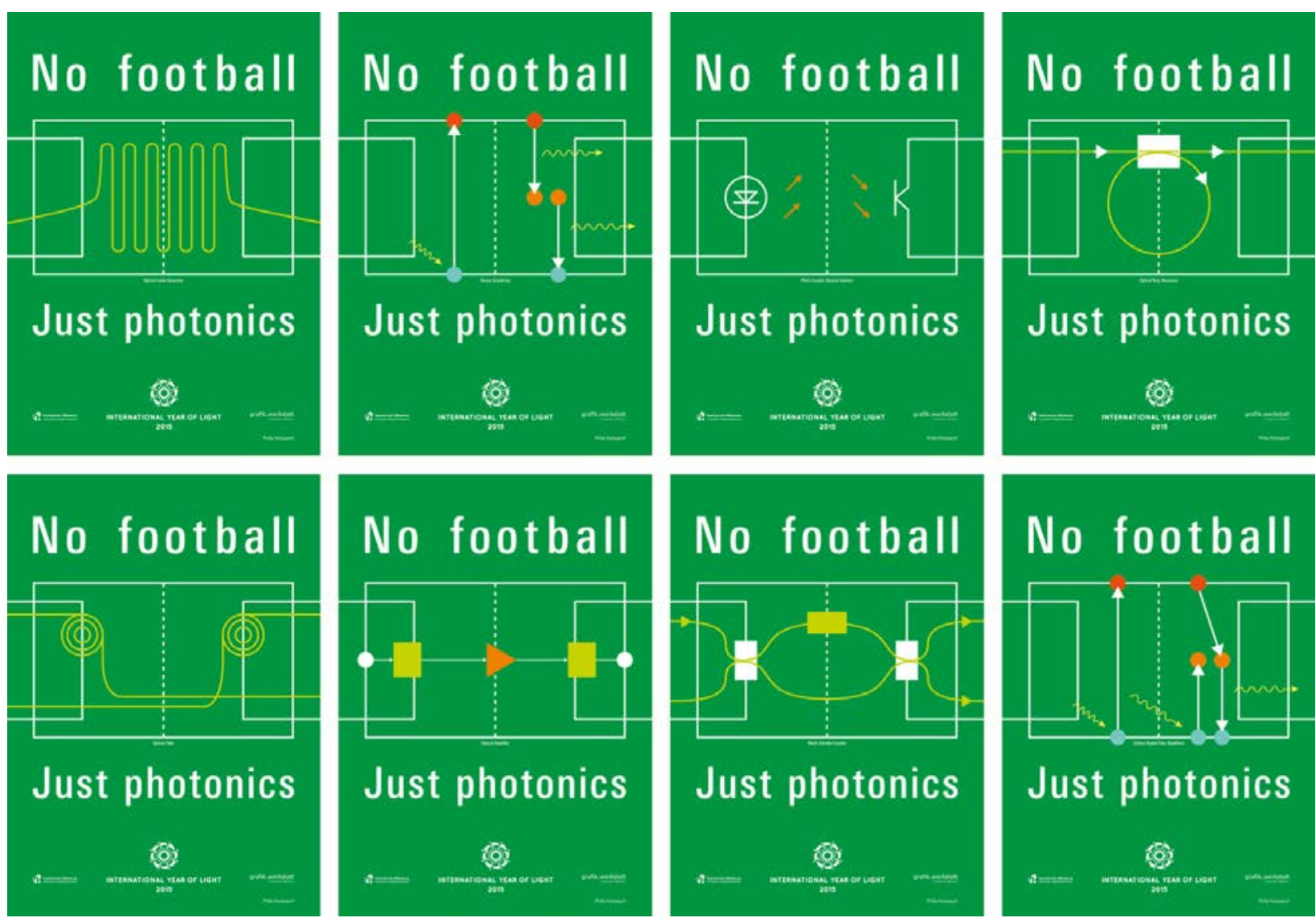

Fig. 3: Artwork Poster: No football - Just Photonics; (C) Phillip Hastigsputh and Dan Curticapean

The feedback on the first presentations of the poster series to the optical community (SPIE - International Society for Optics and Photonics, OSA - Optical Society of America, EPS - European Physical Society) [7] was exceedingly positive. After receiving a large number of requests, we decided to make the students' designs accessible to the worldwide community.

To achieve the most far-reaching effect, we have offered the posters for download from a website. Over 10,000 posters have been downloaded from this website worldwide, far exceeding our expectations. 


\section{PHOTOGRAPHY ART PROJECTS DEDICATED TO OPTICS AND PHOTONICS EVENTS}

Motivated by the success during the International Year of Light, we continued to involve our students in interdisciplinary projects. Not uncommonly, the best results are achieved when participants from different fields work together on the same topic. In our case it was media students teaming up with students for the teaching profession. This time we wanted to create a motif for the International Day of Light. We integrated the topic into the regular curriculum, where the lecture on photography and lighting appeared the best choice. On the subject of long-term exposure and light painting, we elaborated on a practical application; the mentioned stylistic methods were used, but digital processing was also necessary. The result is shown in Figure $4 b$.
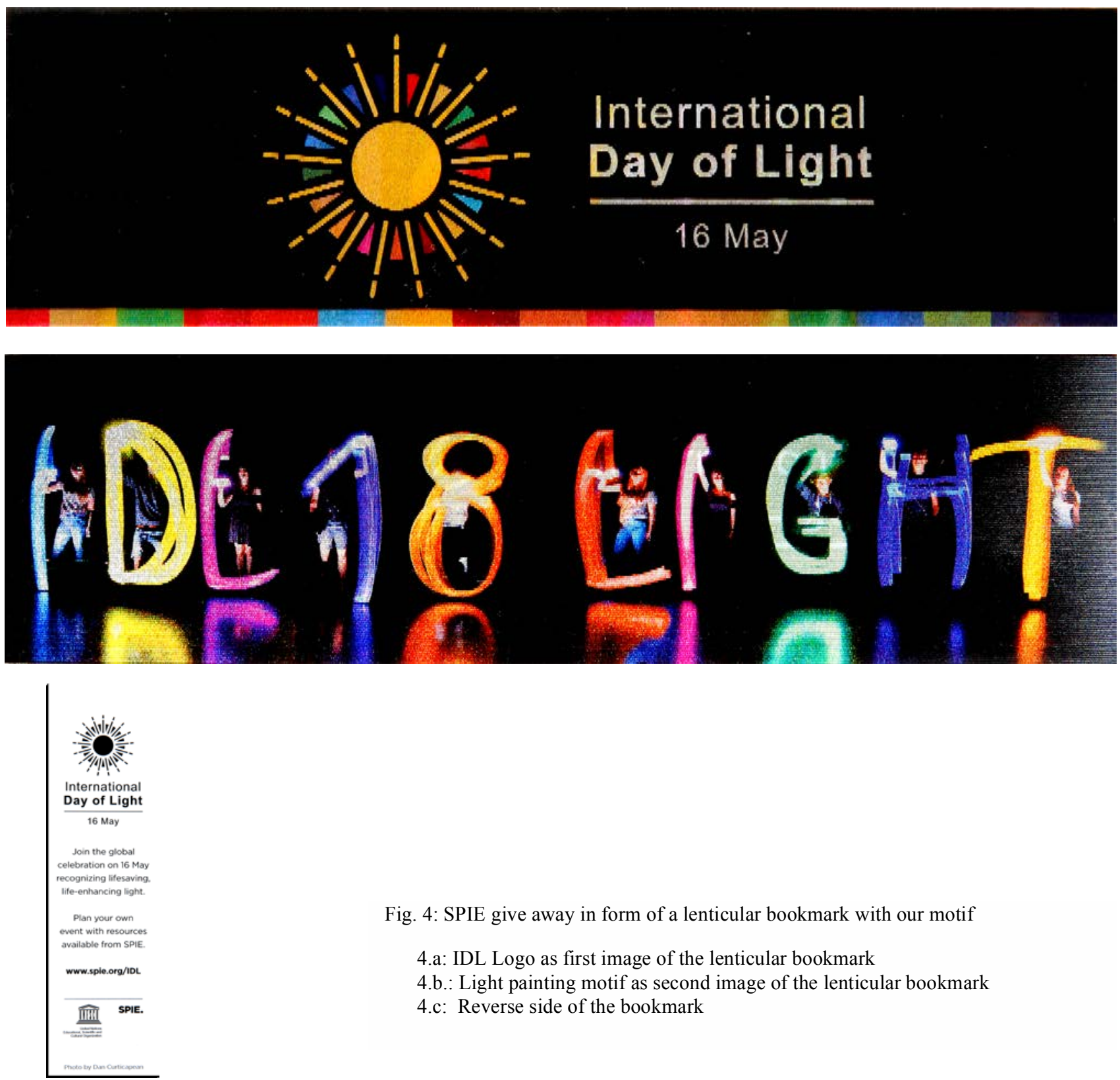

Fig. 4: SPIE give away in form of a lenticular bookmark with our motif

4.a: IDL Logo as first image of the lenticular bookmark

4.b.: Light painting motif as second image of the lenticular bookmark

4.c: Reverse side of the bookmark 
Another objective of the lecture was to participate in the photo contest. To our pleasure, our work was selected as the top of about one thousand submissions. We were all the more joyful to see our photo on the SPIE poster at the IDL Inauguration Ceremony at the UNESCO Headquarter in Paris (16 May 2018), and also as a SPIE give-away in form of a lenticular bookmark (Fig. 6-9). Lenticular prints undergo a special image processing system featuring a particularly high optical effect. This makes it possible to display several different source images in a single print.

The IDL Steering Committee also selected our motif for the long-term advertising (Fig. 4).

Our interdisciplinary work involving science and art has been concretized in scientific photographs, often using the microscope as an objective. The photos shown in Figure 5 were taken with the help of a Leica microscope that can operate with polarized light. The photograph shows citric acid which was initially dissolved in water and then dried. This way the citric acid was recrystallized and the new crystals were flatter and thinner, so we could realize the desired light effects and colors with polarized light. It was crucial to produce the thin and flat crystals, because this is the key to creating different optical paths. The differences of the optical paths in polarized light produce the spectacular light effects. To provide the image a certain calmness, respectively to increase the symmetry, the image was duplicated and mirrored around the $y$-axis and then added to the original image. The sample preparation and original recordings were carried out by Edeltraut Veit-Kiefer and the post production and digital mastering by the author. (Fig. 5)

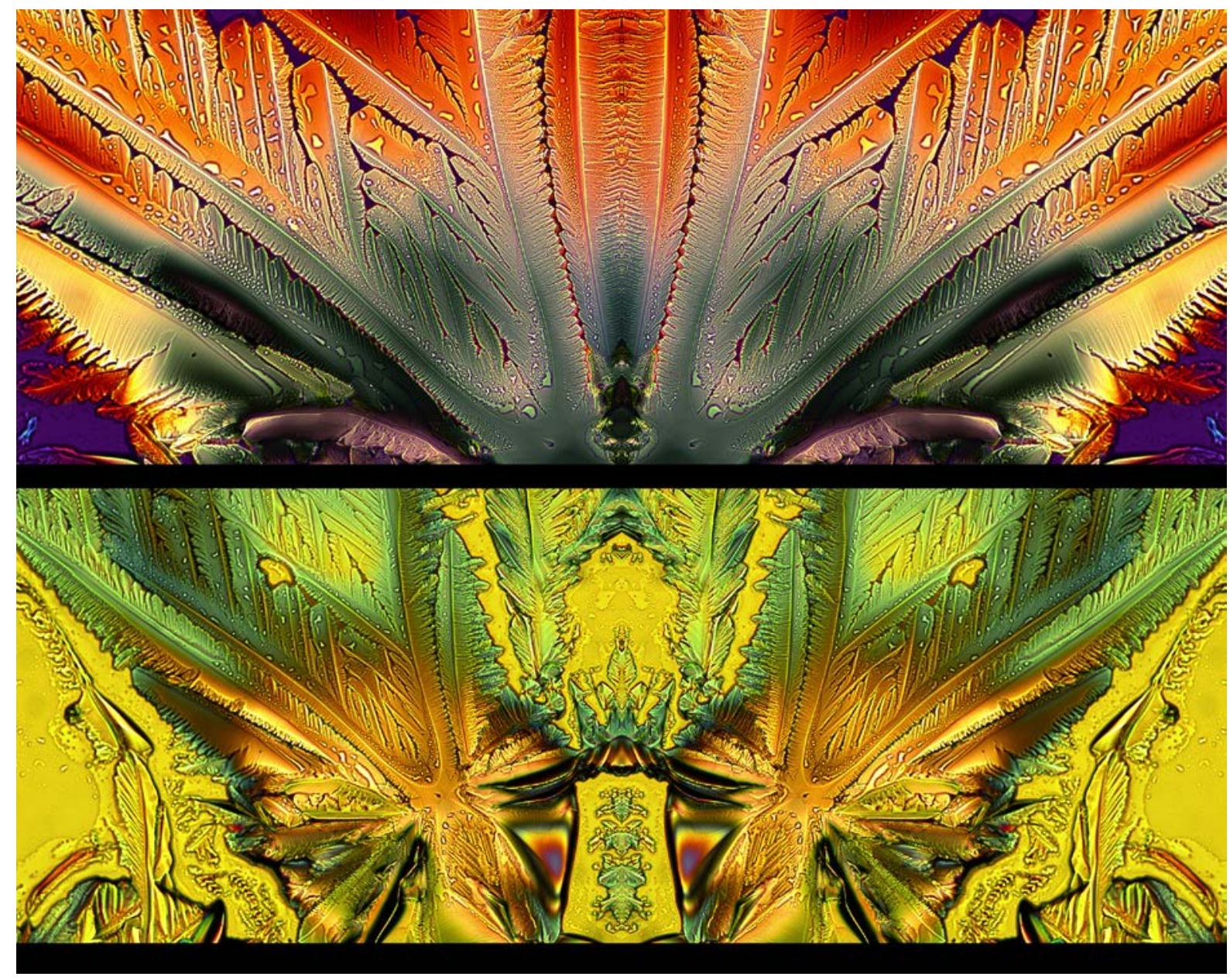

Fig. 5: Photograph of dried citric acid; recorded with a light microscope using polarized light (C) Edeltrat Veit-Kiefer \& Dan Curticapean 
The scanning electron microscope (SEM) also played a special role in our cooperation between science and art. In contrast to the light microscope, the SEM does not use photons but electrons. This results in high magnifications of the examined objects and opens new doors for the investigation of nanoworlds. Only black and white images are created, which are then processed by digital mastering (Fig. 6).

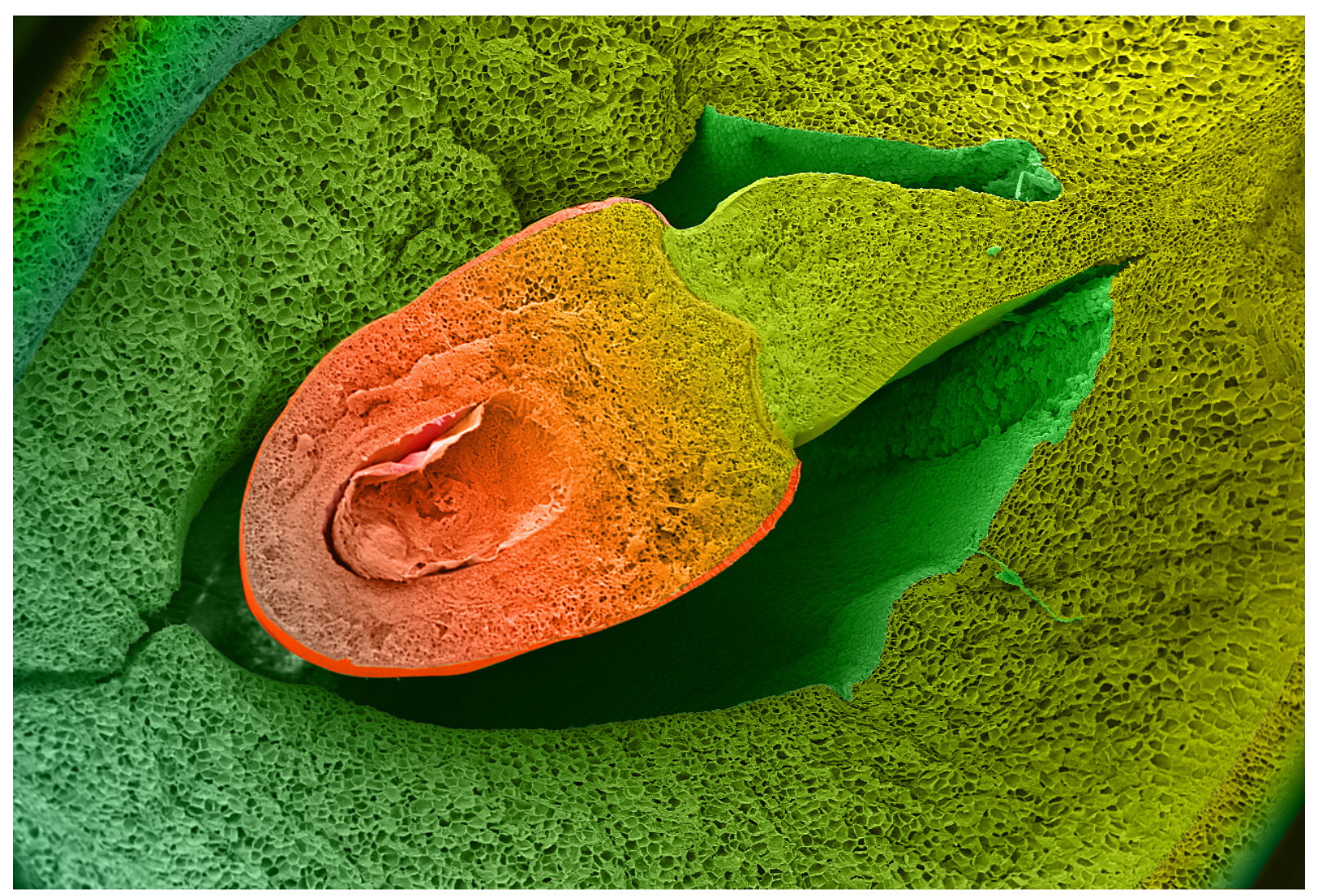

Fig. 6: Cross section through a bean.; (C) Dr. Pascale Müller and Dan Curticapean

\section{4. “THE POWER OF YOUR EYE" AN INTERACTIVE INTERDISCIPLINARY ART AND PHOTONICS PROJECT}

"The Power of Your Eye" is an interactive media installation based on the principle of eye tracking. The interaction is described on the postcard presented in Figure 7. The viewer looks at the screen and fixes their gaze on one of the circles on it. The fixated circle then begins to rotate; when it is fixated again, it comes to a standstill. To determine the position of the gaze, an eye-tracking bar is attached to the lower edge of the screen. In our media installation, a commercial eyetracking bar was used. It takes over the movement of the computer mouse, and is controlled accordingly by the participant's image.

The animation of the circles was programmed with Adobe Flash. The circles themselves are the result of different patterns created with ten LEDs on a rotating disk by long-term exposure. A special challenge was the calibration of the eye-tracking bar in order to match as large a number of participants as possible without calibrating for each individual. 

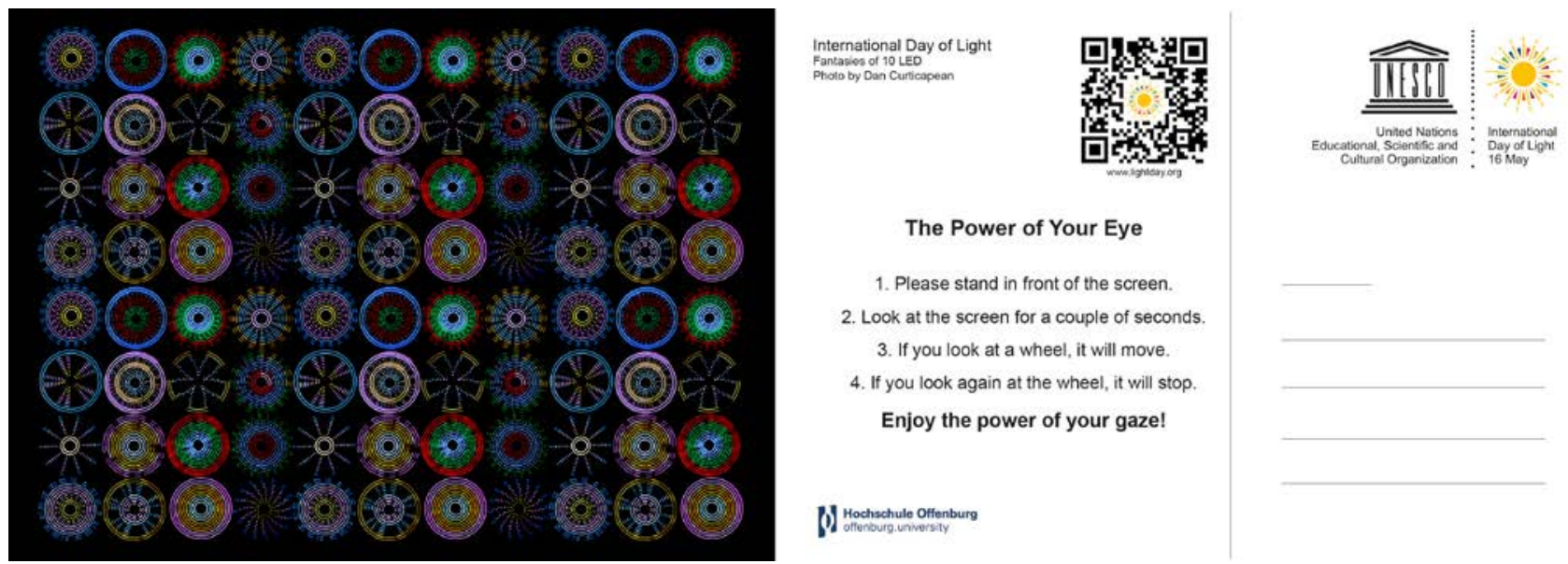

Fig. 7: The Power of Your Eye - Postcard with instructions on how to interact with the installation.

\section{5. „A MAZE: INGENIOUS PIPES” AN INTERACTIVE PROJECTION AND PHOTO SHOOTING}

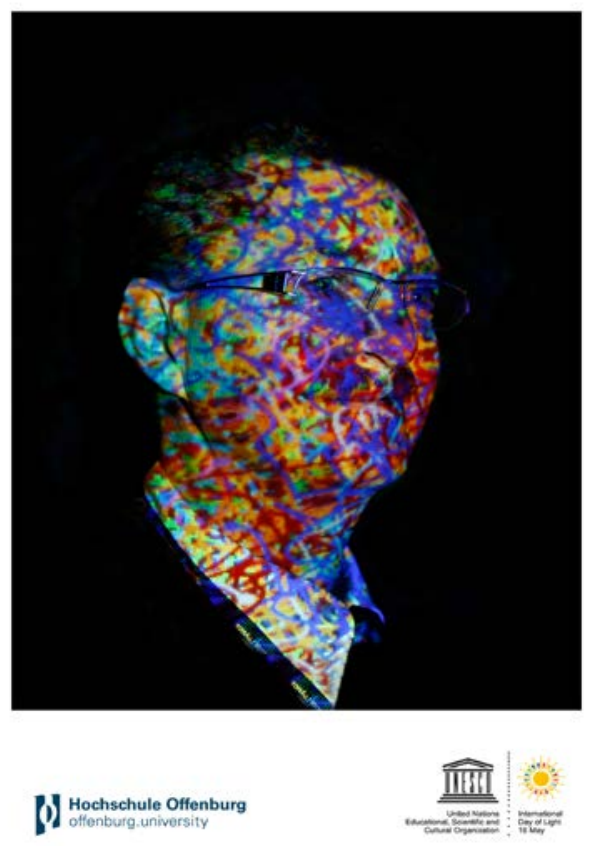

"A Maze: Ingenious Pipes" is an interactive project involving projection and photography. In a dark room, a pattern is projected onto the participants. The pattern is randomly generated by a computer and has an evolving shape similar to dendritic growth. The participants are given a self-timer and see themselves in a control monitor. Depending on the pattern the participant can trigger the timer and have the image printed out as a Polaroid photograph. Figure 6 shows Mister International Day of Light, John Dudley's result.

This project engaged a group of students, who had to bring in their combined knowledge of computer science, electrical engineering, design and photography to master the installation. Meanwhile we have added an extension such that the resulting image is sent to the participant's mobile phone and can be viewed in $3 \mathrm{D}$ using a cardboard.

Fig. 6: Result of "A Maze: Ingenious Pipes" in a "Polaroid" photograph (John Dudley) 


\section{INTERNATIONAL DAY OF LIGHT ART POSTCARD COLLECTION}

To focus the attention on the International Day of Light, this author had designed a series of postcards in advance. The series was a synergy of physical experiments, photography and image processing. The results are presented in Figures $11-16$.
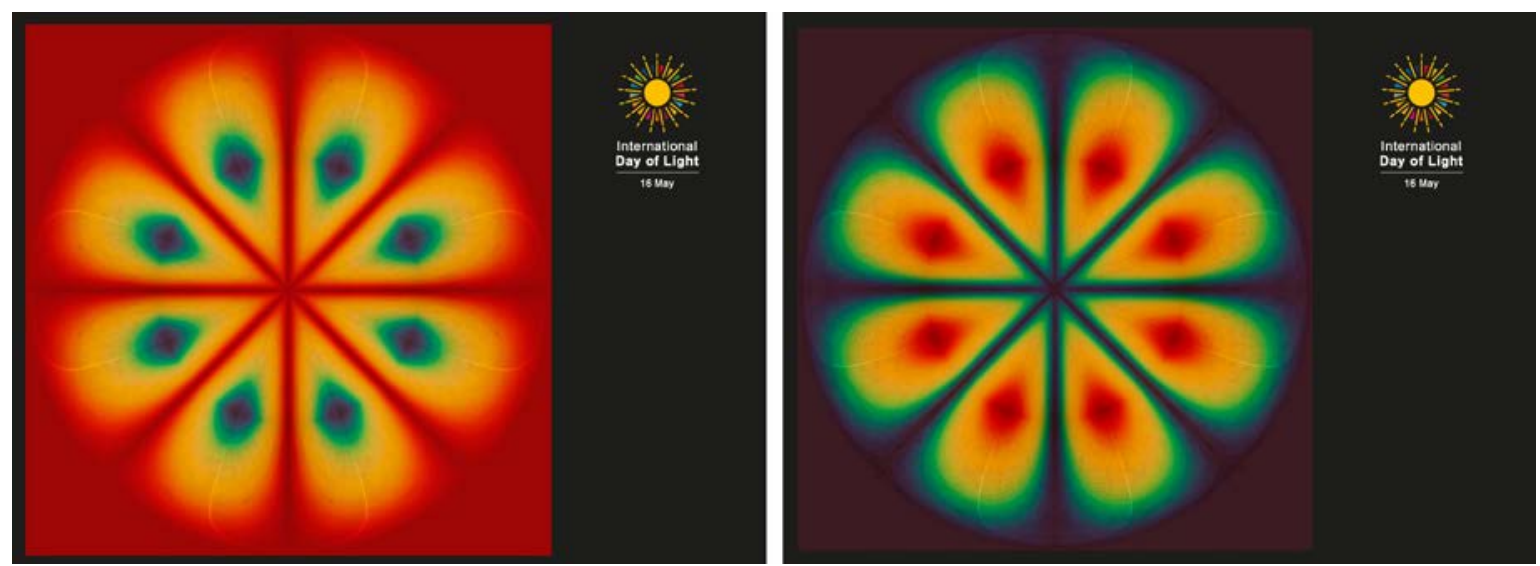

Fig. 11 - 12: Postcards IDL: Orbital Light Red - Orbital Light Blue; C Photos Dan Curticapean
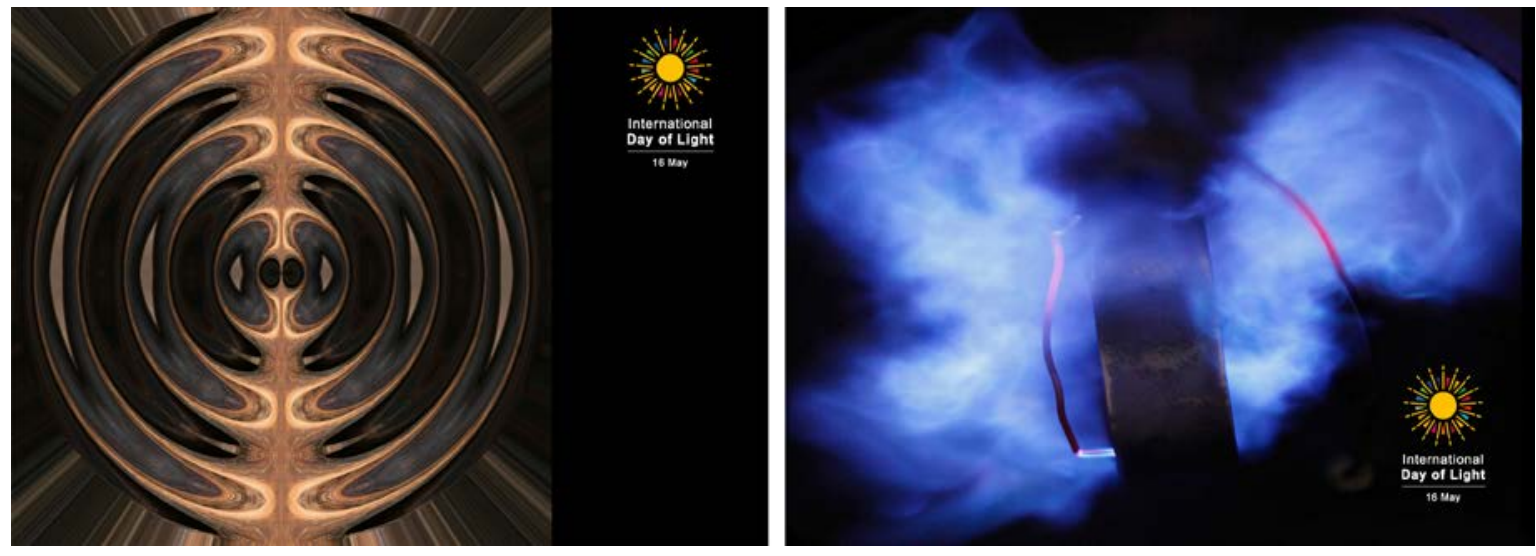

Fig. 13-14: Postcards IDL: Electromagnetic Waves - The Light Inside the Engine; @ Photos Dan Curticapean
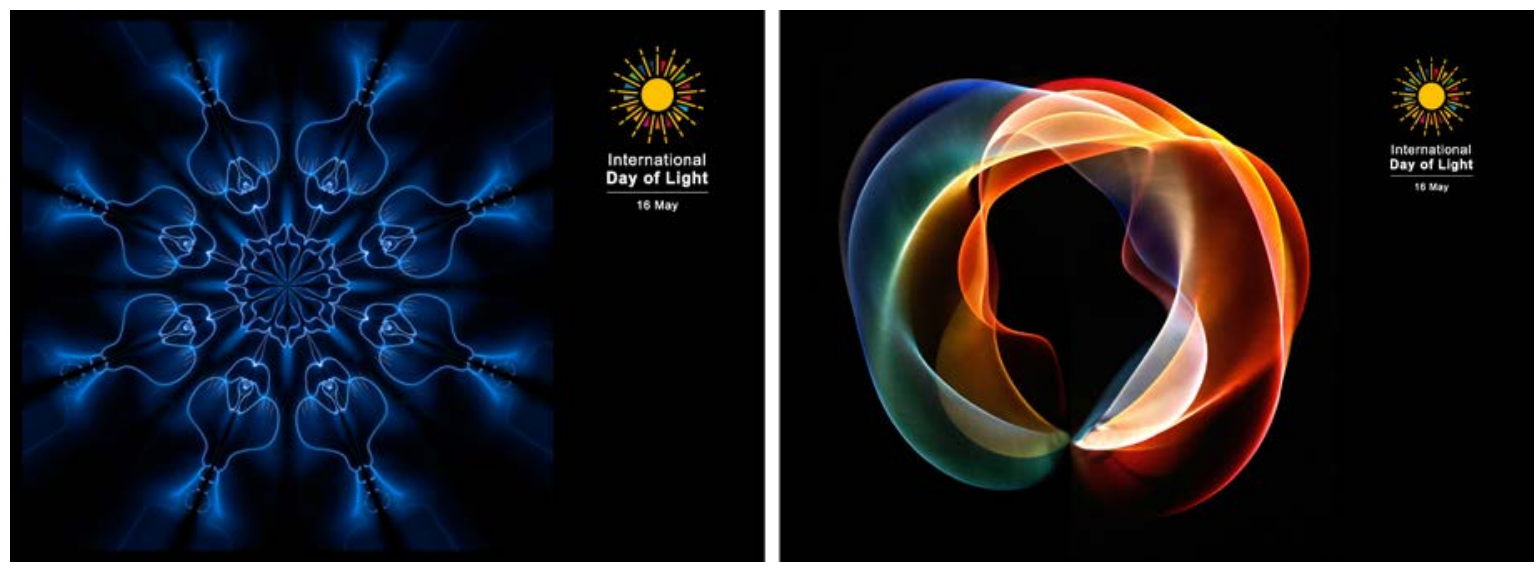

Fig. 15 - 16: Postcards IDL: Plasma Pseudosymmetry - Optical Möbius Strip II; @ Photos Dan Curticapean 


\section{7. „TWITTERWALL“ AN INTERACTIVE LIVE PROJECTION}

The interactive projection (Fig. 4) was shown in the foyer of the Paris UNESCO building during the inaugural ceremony of the International Day of Light at 18. May 2018, next to works by Picasso or Miró. Tweets placed for the inaugural ceremony by participants around the world - not just those present in Paris - were visualized and presented in an interactive projection. Using the hashtag \#idl2018, Twitter messages could be sent to Paris and were then placed on a rotating globe showing the users' locations and messages. The interactive map highlighted the regions from which tweets originated in different colors. According to the number of tweets, the colors of the regions also changed, from yellow to dark red. In addition, the projections were streamed onto the IDL2018 website, so the participants were able to receive feedback and actively participate in the opening even if they not be there.

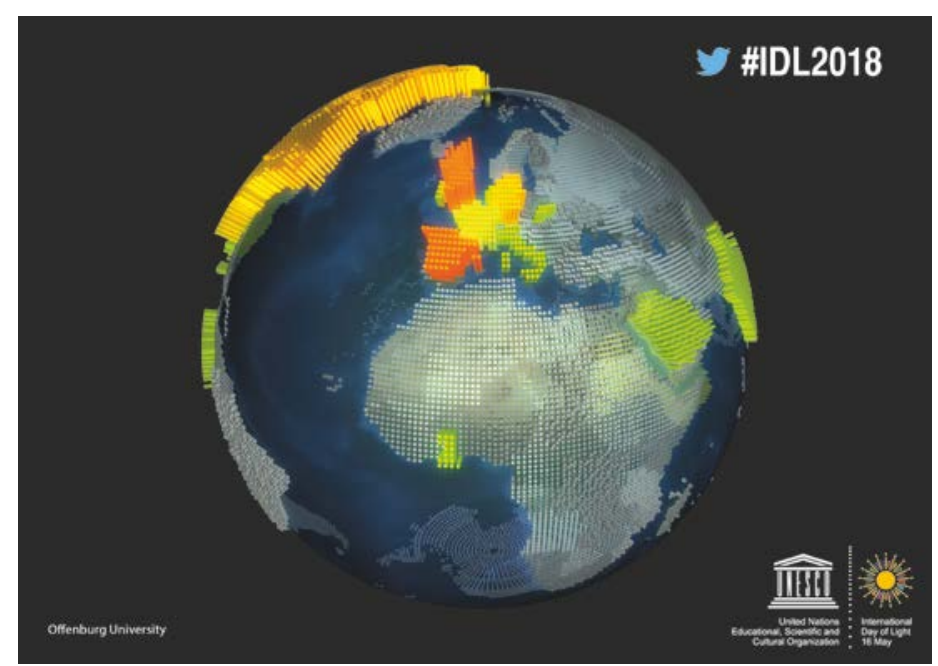

Fig. 4: Twitterwall for the IDL inaugural ceremony at UNESCO Paris

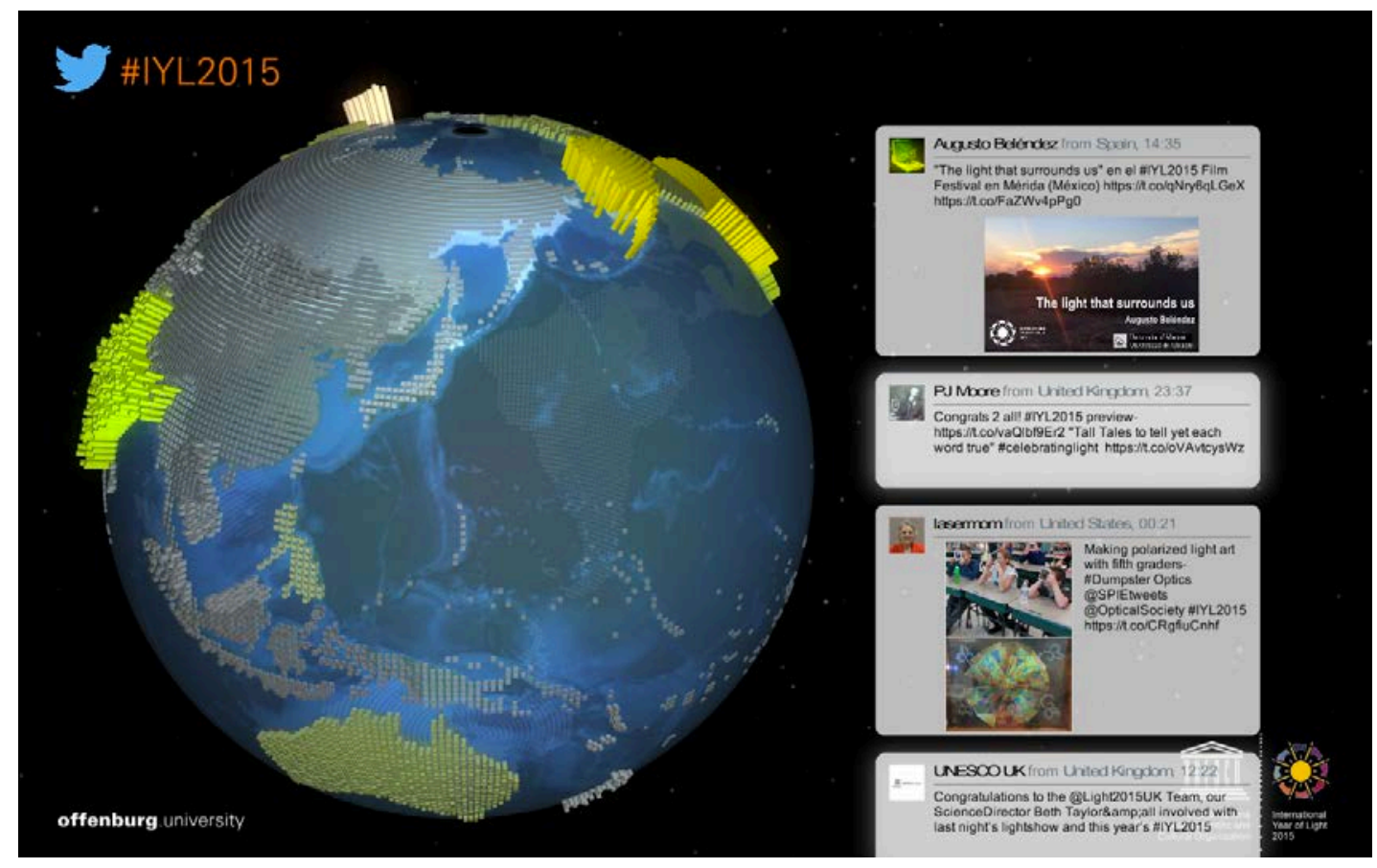

Fig. 5: Twitterwall screen shoot of a visualized tweet from the "lasermon" Judy Donnely during the IYL 


\section{CONCLUSIONS AND PERSPECTIVES}

We have been very happy about this opportunity to present our students' works to the world at the same time as supporting the special cause of making the IDL happen and publicizing it. The project continues to be exciting. With it we hope to awake young people's interest and enthusiasm for physics, and for optics in particular, as a science of the future.

\section{REFERENCES:}

[1] Ang, T., [Photographie], Dorling Kindersley Limited, London (2005)

[2] Barringer, T., Devaney E., Drabble, M., Livingstone, M., Gayford, M., Salomon, X. F., [David Hockney: A Bigger Picture], Royal Academy of Arts, London (2012)

[3] ***, ,Johannes Gutenberg,“ https://de.wikipedia.org/wiki/Johannes_Gutenberg, (30 April 30 2019)

[4] ***,,„Buchdruck,“

[5] Elgammal, A., „Informatik - Kreative Computer,“ Spektrum der Wissenschaft, 5/2019, p.68-72; Spektrum der Wissenschaft Verlagsgesellschaft mbH Heidelberg (2019)

[6] Curticapean, D., „Photonics is a player at the FIFA World Cup,“ $<$ http://spie.org/x108899.xml> (2014)

[7] Huchet,B., "IYL 2015 - Draw the magic of light", EPS, 27. Feburary 2014, http://www.epsnews.eu/2014/02/iyl2015-magic-of-light/ (30 April 2019) 